\title{
ПРОТОКОЛЫ ЗАСЕДАНИЙ СЕКЦИИ СЕРДЕЧНО-СОСУДИСТОЙ ХИРУРГИИ И АНГИОЛОГИИ ХИРУРГИЧЕСКОГО ОБЩЕСТВА ПИРОГОВА
}

\author{
Председатель общества - А.С.Немков; ответственный секретарь - Н.А. Гордеев
}

\section{7-е заседание 18.03.2015 г.}

Председатель - А.С.Немков

\section{ДЕМОНСТРАЦИЯ}

И.А.Пятериченко, Е.А. Лесковский, А.Б.Шляховой, В.К.Григорян, А.А.Бояркин (ГМПБ № 2, Городской кардиохирургический центр, Санкт-Петербург). Протезирование клапана аорты через мини-доступ.

Больной Н. поступил в ГМПБ № 2 с диагнозом «хронический инфекционный эндокардит, ремиссия, выраженная недостаточность аортального клапана, ХСН 3 ф. кл.». В связи с нарастающими явлениями сердечной недостаточности в декабре 2014 г. выполнена операция протезирования аортального клапана через мини-доступ: парциальная срединная стернотомия до уровня четвертого межреберья с продолжением разреза в виде мини-торакотомии по четвертому или пятому межреберью. Обнажение восходящей аорты и правого предсердия было достаточным для подключения аппарата искусственного кровообращения. Косопоперечный разрез аорты обеспечивает удовлетворительную визуализацию клапана для иссечения его створок и имплантации протеза. Мини-доступ обеспечивает сохранность грудины, больные раньше могут начинать заниматься лечебной физкультурой в связи с отсутствием нестабильности грудины.

Ответы на вопросы. Эндокардит аортального клапана чаще встречается. Доступ выполняли до четвертого межреберья. Мини-инвазивный доступ лучше использовать по показаниям.

\section{ДОКЛАДЫ}

1. И.А.Пятериченко, Е.А. Лесковский, А.Б.Шляховой, В.К.Григорян, А.А.Бояркин (ГМПБ № 2, Городской кардиохирургический центр, Санкт-Петербург). Бесшовные клапаны в хирургии аортальных пороков сердца.

Бесшовные клапаны (Perseval, SORIN) используются в мире более 20 лет. Конструкция клапана - металлический стент и створки из бычьего перикарда. Специальное покрытие - Carbofilm обеспечивает самозакрепление стента в натуральном декальцинированном клапане с удаленными створками, не перекрывая устья венечных артерий. Сокращение времени операции при простоте и удобстве имплантации - важные положительные компоненты этой операции. Цилиндрический тип открытия створок обеспечивает уменьшение градиента давления и турбулентности потока. Якорная технология посадки обеспечивает «истинно» бесшовную технику имплантации. Показания: взрослые пациенты (65 лет и старше) со стенозом или сочетанным пороком аортального клапана; аортальное кольцо диаметром 19-25 мм. Противопоказания: изолированная аортальная недостаточность, врожденный двустворчатый аортальный клапан, дилатация корня аорты. Первые 3 имплантации бесшовного клапана показали хорошую переносимость операции больными, длительность операции существенно меньше (на 30-40 мин). Функция имплантированного биологического протеза удовлетворительная в ближайшем послеоперационном периоде и будет прослежена нами в отдаленном периоде.

Ответы на вопросы. Размер клапанов зависит от эластичности аорты, кальциноза и т. д.

Опыта трансапикального протезирования аортального клапана нет. Защита левой венечной артерии обеспечивалась высоким рассечением аорты, тщательной декальцинацией, измерением протеза.

Кардиоплегия осуществлялась без особенностей.

\section{Прения}

В.К.Сухов. У нас опыт более 30 трансаортальных трансплантаций, 4 неудовлетворительные, но все остальные - с хорошим результатом. Учитывая наш опыт, могу утверждать, что больному, которого сегодня демонстрировали, лучше было бы выполнить трансаортальное катетерное протезирование аортального клапана.

В.М.Седов.Трудно дать комментарии к этому докладу, но опыт очень интересный, он первый. Нужно набирать опыт и делать новые доклады. Спасибо за хорошее сообщение.

2. Г.Г.Хубулава (главный кардиохирург СанктПетербурга). О состоянии кардиохирургической помощи в Санкт-Петербурге в 2014 г. и задачах на 2015 г.

Смертность от сердечно-сосудистых заболеваний остается главной в структуре общей смертности в нашей стране и составляет $50,4 \%$. Число операций на сердце стабильно увеличивается в нашей стране за последнее пятилетие и составляет при ИБС 36632 операции аортокоронарного шунтирования (АКШ). В нашем городе выполняется более 3000 операций АКШ, что незначительно меньше расчетной потребности - 3500, по аналогии с европейскими странами. Операции при клапанных пороках -850 операций, что также приближается к потребностям нашего города.

Коронарная ангиопластика и стентирование - выполнено более 9500 (расчетный показатель соответствия европейским рекомендациям - 14 тыс. процедур в год в Санкт-Петербурге), более половины из них приходится на пациентов с острыми расстройствами коронарного кровообращения. Около $1 / 3$ процедур коронарной ангиопластики и больше половины операций с искусственным кровообращением (ИК) выполняет ФЦСКЭ им. В.А. Алмазова.

Центры, работающие с ИК: ФЦСКЭ им. Алмазова, клиника ХУВ-1 им. Куприянова ВМедА, Медсанчасть № 122, ПСПбГМУ им. акад. И.П.Павлова, Городской кардиохирургический центр на базе ГМПБ № 2, СевероЗападный государственный медицинский университет им. И.И.Мечникова, Ленинградская областная клиническая больница, Детская городская больница № 1, СПбНИИСП 
им. И.И. Джанелидзе, Мариинская больница, Городская больница № 40.

Стационары, не имеющие оборудования для ИК, выполняющие операции на сердце (противоаритмические, эндоваскулярные): СПКК Национального медикохирургического центра им. Н.И.Пирогова, Городская больница № 26, Городская больница № 31, Покровская больница, Госпиталь ветеранов войн, Кардиоклиника, Ленинградский областной кардиологический диспансер.

Необходимые изменения в соответствии с потребностями города: интенсификация работы в существующих стационарах, упор в рутинных операциях на городские больницы, упорядочение системы распределения квот, следует более четко соблюдать распределение зон ответственности между конкретными центрами в рамках Санкт-Петербурга.

Следует продолжить курирование крупными федеральными центрами стационаров муниципального подчинения для внедрения новых кардиохирургических технологий в практическую работу больниц с уже сформированными потоками плановых и экстренных пациентов. Остается серьезной проблема хирургического лечения пациентов с расслаивающими и предразрывными аневризмами аорты. Необходима программа финансирования для ряда нозологических форм: наиболее значимой проблемой остается хирургическое лечение инфекционного эндокардита и острых расслоений аорты. Необходим внутригородской регистр оказания кардиохирургической помощи пациентам. Начать следует с ишемической болезни сердца.

Ответы на вопросы. Больных с экстренным кардиохирургическим лечением никто не берет, в том числе в кардиоцентр. Мы этот вопрос неоднократно обсуждали в городском управлении здравоохранения, необходимо улучшать кардиохирургическую помощь в городских больницах, обучать молодых хирургов, самим учиться, ездить в другие города и центры, участвовать в этих операциях, необходимо создать собственных городской регистр и контроль качества работы всех сотрудников.

Больных с гнойными осложнениями после кардиохирургических операций необходимо лечить там же, где выполнена основная хирургическая операция, но в отдельной палате.

При остром коронарном синдроме, когда не получается стентирование и требуется АКШІ, следует переводить пациента на канал финансирования по высокотехнологичной помощи и в тот же день оперировать. Решение должен принимать кардиохирург. В хорошем коллективе так и есть.

В.М.Седов (председатель). Эффект новых технологий - это бюрократизация, непонятное разделение категорий больных, непонятное и недостаточное финансирование. Однако в таких условиях мы все равно должны оказывать качественную высокоспециализированную помощь больным с заболеваниями сердца. Достойным примером является ВМедА.

Поступил в редакцию 31.05.2017 г.

\section{8-е заседание 15.04.2015 г.}

Председатель - В.Н.Вавилов

\section{ДЕМОНСТРАЦИЯ}

В.И.Пан, Н.А.Гордеев, Т.И.Кагачева (Кафедра факультетской хирургии ПСПбГМУ им. акад. И.П.Павлова). Отдаленные результаты кава-клипирования - 10 лет после илеофеморального флеботромбоза с флотирующим тромбом.

Кава-клипирование как метод профилактики тромбоэмболии легочной артерии при флеботромбозе нижних конечностей и вен таза используется более 30 лет. За последние 10 лет проведен анализ результатов этого метода лечения. Отличие кава-клипсы (разработана д-ром мед. наук. Н.А.Гордеевым) от кава-фильтра заключается в том, что кава-клипса применяется экстравазально и не травмирует внутреннюю эндотелиальную выстилку нижней полой вены, модифицируя её просвет таким образом, что крупный тромб не сможет пройти через гофрированную клипсой зону сосуда. При этом не создается условий для формирования тромба в месте установки клипсы, так как отсутствует травма эндотелия, а скорость кровотока в суженой части вены увеличивается.

В 2006 г. больной Л., 34 лет, поступил в клинику по экстренным показаниям. На основании жалоб и инструментальных методов исследования поставлен диагноз: «острый илеофеморальный тромб с флотацией, более 5 см, распространяющийся до уровня общей подвздошной вены восходящий флеботромбоз». Выполнена хирургическая операция - кава-клипирование в инфраренальном отделе кава-клипсой конструкции кафедры факультетской хирургии (Н. А. Гордеев. В.М.Седов). В 2015 г. выполнена контрольная рентгенограмма зоны кава-клипсы (проходимость НПВ не нарушена, клипса не смещена). На сегодняшний день пациент чувствует себя удовлетворительно. Уровень жизни не снижен.

Наблюдение за более чем 200 больными (ретроспективная и проспективная части исследования) показали, что кава-клипирование совместно с применением антикоагулянтной терапии эффективно помогает в профилактике тромбоэмболии легочной артерии у больных, ранее перенесших тромбоэмболии и имеющих илеофеморальный тромбоз.

Ответы на вопросы. Временные кавафильтры не всегда удается удалить, и они остаются на всю жизнь и, как правило, приводят к тромбозам.

Медикаментозная поддержкадля больного с кава-клипсой должна заключаться в назначении низкомолекулярного гепарина до выписки больного из стационара, затем больного переводят на варфарин под контролем МНО $(2,0-3,0)$ либо ксарелто, который он принимает не менее 6 мес, необходимо обязательно использовать компрессионный трикотаж.

\section{Прения}

В.Н.Вавилов (председатель). Поздравил авторов $\mathrm{c}$ хорошей демонстрацией и хорошими результатами лечения больного по предложенной методике, разработанной на кафедре факультетской хирургии еще 30 лет назад.

\section{дОклАДЫ}

1. И.Н.Сонькин, А.С.Ремизов, Д.В.Крылов, В.Ю.Мельник, А.И.Атабеков (НУЗ «Дорожная клиническая больница» ОАО РЖД Санкт-Петербурга, отделение сосудистой хирургии). Инновации импортозамещающих технологий в лечении венозных тромбоэмболических осложнений.

Правительство РФ планирует обеспечить российский фармрынок отечественными лекарствами на $90 \%$ к 2018 г. Из 608 импортируемых жизненно необходимых лекарств около 400 производится в России. Мы хотим поделиться 
опытом применения отечественного препарата Тромбовазим в лечении тромбоза глубоких вен нижних конечностей (ТГВ).

Современное лечение ТГВ направлено на предотвращение прогрессирования тромбоза, формирования флотирующих тромбов и тромбоэмболии легочной артерии, рецидива тромбообразования. Но часто упускают из виду формирование посттромботического синдрома.

До сих пор не было единого мнения относительно тактики лечения ТГВ. До последнего времени мы придерживались следующей тактики. Если возраст тромба не более 12-14 дней, то мы применяли регионарный катетер-управляемый тромболизис; при существовании тромба более 14 дней использовали стандартные схемы консервативного лечения.

В своей практике мы использовали только катетеруправляемый тромболизис. Эти операции стали рутинными в практике нашего отделения, пока не поступил пациент Г., 45 лет, с левосторонним илеофеморальным флеботромбозом в анамнезе (2013 г.), полгода назад самовольно отказался от приема варфарина. Жалобы при поступлении на сильный отек, боли в правой ноге, посинение кожи ноги, развившиеся за 3 дня до госпитализации. Наблюдаются цианотичность, отек, захватывающие область от пальцев до паха. Дуплексное сканирование подтвердило правосторонний илеофеморопоплитеальный тромбоз. При антероградной флебографии выявлен окклюзионный тромбоз подвздошного сегмента справа и флотирующий тромб в нижней полой вене (4,5 см) выше уровня впадения почечных вен. Любой из возможных способов лечения (хирургическая тромбэктомия, эндоваскулярная тромбэктомия, консервативное лечение) приведет лишь к формированию стойкого посттромбофлебитического синдрома либо (катетер-управляемый тромболизис с временным кава-фильтром) технически и финансово значительно усложнит процедуру.

Принято решение ввести в схему лечения данного пациента отечественный препарат тромбовазим, который представляет собой комплекс очищенных протеолитических ферментов - субтилизинов. Механизм действия препарата основан на прямом неспецифичном тромболизисе, т. е. происходит непосредственное прицельное разрушение каркаса тромба. Тромбовазим воздействует только на нерастворимый денатурированный белок (фибрин) и клеточный детрит, поэтому при его применении отсутствует системное действие на гемостаз. Кроме того, препарат обеспечивает морфологически краевой тромболизис, по типу тающей сосульки. При этом отсутствует взрывная фрагментация, а значит, нет эмбологенности.

Больному проведено стандартное консервативное лечение (низкомолекулярные гепарины в лечебных дозах, препараты, улучшающие реологические показатели крови, эластичный трикотаж, перемежающаяся пневмокомпрессия), в схему которого введен системный тромболизис в виде внутривенной инфузии 10000 МЕ тромбовазима. Каких-либо нежелательных явлений, побочных эффектов, осложнений не зафиксировано. Достигнуто клиническое улучшение в виде значительного уменьшения отека конечности, нивелирования болевого синдрома, нормализации цвета ноги. При мультиспиральной компьютерной ангиотомографии, произведенной через 3 дня после тромболизиса, видна реканализация тромботических масс в нижней полой вене и полный лизис флотирующей головки тромба.

Такие свойства препарата, как дозозависимое растворение тромба и низкий риск осложнений, отсутствие аллергических и анафилактических реакций, отсутствие ток- сического действия, возможность многократного применения и небольшая стоимость тромбовазима определяют новые возможности решения давней проблемы. В случае подтверждения наших предположений тромболизис можно применять при наличии любого тромба, при любых локализациях, без опасности развития геморрагических осложнений.

Хорошие непосредственные результаты применения препарата тромбовазим требуют проведения дальнейшего углубленного исследования.

Ответы на вопросы. Доза тромбовазина $20000 \mathrm{ME}$ через инфузомат внутривенно. Венарус дешевле и меньше воздействует на желудочно-кишечный тракт.

Катетерный тромболизис выполняется проведением катетера через тромботические массы, начиная с верхушки через флотирующую часть. Все рекомендуют при тромбе с флотированием больше 6-7 см ставить кава-фильтр.

Использовали катетеры пигтейл с проводником. Тромбоэмболий не было ни разу.

Результаты ультразвуковой допплерографии часто не коррелируют с клиникой ПТФС.

\section{Прения}

Н.А.Гордеев. Нужна монография или методичка для более широкого внедрения методики.

В.Н.Вавилов (председатель). Очень хороший доклад, соответствует международным стандартам подхода к этой проблеме.

2. В.В.Сорока (главный ангиохирург Санкт-Петербурга). О состоянии ангиохирургической помощи в СанктПетербурге в 2014 г. и задачах на 2015 г.

Проблема атеросклеротического поражения аорты и ее ветвей остается актуальной как для всей страны, так и для Санкт-Петербурга. Поражение брюшной аорты, брахиоцефальных и артерий нижних конечностей не уменьшается, несмотря на активное консервативное лечение атеросклероза терапевтами. Распространенность цереброваскулярных болезней в России в 2014 г. составила 6105 на 100 тыс. жителей. От инфаркта мозга в 2014 г. в стране умерли более 266 тыс. людей. Операций на брахиоцефальных артериях выполнено более 2080 в городских и федеральных учреждениях нашего города. Операции на периферических артериях в Санкт-Петербурге в 2014 г. выполнены более 1900 больным, более 900 больным выполнены реконструктивные операции на аортобедренном сегменте. Операции при аневризме брюшной аорты выполнены 185 пациентам.

Более 4000 пациентов получили хирургическую помощь при заболеваниях вен.

Проблемы, выявленные в прошедшем году, представлены недостаточным финансированием высокотехнологичных операций при острых патологических состояниях - расслоении аорты, которое, как правило, требует имплантации аортального стент-графта.

Появилась возможность стентирования артерий голени при критической ишемии нижних конечностей, однако финансирование для эндоваскулярных и гибридных операций при этой неотложной ситуации оставляет желать лучшего.

Oтветы на вопросы. Количество операций на артериях уменьшается с учетом роста эндоваскулярных процедур во всем мире. Но уменышения числа ангиохирургов, вероятно, не будет.

Установку кава-фильтров за рубежом отменили. В России много подводных камней (экономических и др.). 
Число ампутаций, выполняемых в год в городе, неизвестно, так как статистическая отчетность страдает.

\section{Прения}

Н.А.Бубнова. В нашей больнице производят 110 ампутаций за год. В дежурных больницах города - около 750 ампутаций, из них 136 после сосудистых операций. Центр спасения конечности на «юге» города - в 14-й больнице, а на «севере» такого центра нет, нужна ангиографическая установка.

В.Н.Вавилов выразил благодарность главному ангиологу Санкт-Петербурга В.В.Сороке. Одновременно отметил недостаточную экономическую помощь государства - мало аппаратуры и текущего финансирования»

Поступил в редакцию 31.05 .2017 г.

\section{9-е заседание 20.05.2015 г.}

Председатель - В.Н.Вавилов

\section{ДЕМОНСТРАЦИЯ}

И.Н.Сонькин, Д.В.Крылов, А.И.Атабеков, В.Ю.Мельник, К.А.Кулешов (НУЗ «Дорожная клиническая больница») Мини-доступ при резекции аневризмы брюшной аорты.

Мировая статистика регистрирует неуклонное увеличение заболеваемости аневризмами брюшной аорты (АБА). Частота аневризм, по данным разных исследований, колеблется от 1 до $10 \%$ в популяции. За 2013 г. в России выполнено более 2000 реконструкций, преобладающее количество - традиционные хирургические вмешательства. Эндоваскулярные операции наряду с явными преимуществами перед стандартным лечением имеют отрицательные стороны, главной из которых остается высокая цена. Лапароскопические операции в связи с высокой технической сложностью выполняют в единичных центрах и не рекомендованы для рутинной практики. В данной ситуации актуальна разработка техники мини-лапаротомии - доступа длиной 5-6 см, позволяющего обеспечить достаточную экспозицию аорты.

Пациент 71 года, страдающий ожирением II степени, ГБ ІІ степени, ИБС, пароксизмальной формой фибрилляции предсердий, ХCH I степени. Ранее перенес левостороннюю нефрэктомию по поводу рака левой почки Т2N0M0. При контрольном УЗИ брюшной полости выявлены признаки аневризмы аорты. Диагноз подтвержден данными KT-ангиографии. Диагноз: «средняя веретенообразная аневризма инфраренального отдела брюшной аорты, тип А». Плановая операция 04.10.2014 г.: мини-лапаротомия. Линейное протезирование инфраренального отдела аорты. Длительность операции 160 мин; пережатие аорты 45 мин; кровопотеря 315 мм. Экстубирован на операционном столе, в ОРИТ не находился. Послеоперационный период без осложнений. Выписан на 7-е сутки после операции. Осмотр через 6 мес - послеоперационный рубец без признаков грыжеобразования, пульсация артерий верхних и нижних конечностей сохранена в стандартных точках. В настоящее время жалоб активно не предъявляет, занимается профессиональной деятельностью без ограничений по состоянию здоровья.

Ответы на вопросы. Требуются специальные инструменты для использования мини-доступа.
Специального обучения не требуется. Конверсия потребовалась в двух случаях - это $10 \%$.

Механические ретракторы аорты обеспечивают лучшую её экспозицию, более удобные условия для оперирования, поэтому время пережатия аорты меньше.

\section{Прения}

В.Н.Вавилов (председатель). Следует поздравить авторов демонстрации с хорошим результатом. Однако следует помнить, что в США $60 \%$ составляют эндоваскулярные операции при этом патологическом состоянии и $40 \%$ открытые.

\section{дОклАД}

И.Н.Сонькин, А.С.Ремизов, Д.В.Крылов, В.Ю.Мельник, К.А.Кулешов (НУЗ «Дорожная клиническая больница» ОАО РЖД). Оптимальная нейропротекция при каротидной эндартерэктомии.

Хирургические методы коррекции стенозирующего поражения сонных артерий признаны надежным методом профилактики ишемического инсульта и дают хорошие результаты. Однако два ключевых вопроса до сих остаются открытыми - выбор метода обезболивания операций на каротидном бассейне и условия применения внутрипросветного временного шунтирования.

С 2010 по 2013 г. мы оперировали 158 пациентов с поражением брахиоцефальных артерий. Возраст больных варьировал от 43 до 81 года, в среднем составив $(60,9 \pm 7,93)$ года. Мужчин было $85,4 \%$, женщин - $14,6 \%$. У 31 (17\%) пациента локализация стенозирующего процесса была двусторонней: у 8 - контралатеральные окклюзии и у 23 - контралатеральный гемодинамически значимый стеноз. В связи с этим распределение всех случаев (181) по виду патологического процесса выглядело следующим образом: атеросклероз - 159 (87,8\%) наблюдений, патологическая извитость $-21(11,6 \%)$ наблюдение, диссекция внутренней сонной артерии - $1(0,6 \%)$ случай. Распределение случаев по степени сосудисто-мозговой недостаточности: I степень - 24 (15,2\%) наблюдения, II степень - 32 (20,3\%) случая, III степень - $27(17,1 \%)$ наблюдений, IV степень - $75(47,4 \%)$ случаев. В 47 (26\%) наблюдениях диагностирована нестабильная атеросклеротическая бляшка. В 34 (19\%) случаях обнаружен незамкнутый артериальный круг большого мозга (16 - задняя трифуркация внутренней сонной артерии, 3 - гипоплазия передней соединительной артерии, 15 - отсутствие задней соединительной артерии). Сопутствующие патологические состояния представлены артериальной гипертензией $(93,9 \%)$, ИБС $(66,3 \%)$, сердечной недостаточностью 2-3-го функционального класса $(18,2 \%)$, аритмиями (17\%), сахарным диабетом (13,8\%), хронической обструктивной болезнью легких $(3,3 \%)$.

Bсе больные оперированы под регионарной анестезией (по M.Malroy, 2003). Самым частым хирургических вмешательством была эверсионная каротидная эндартерэктомия - 121 наблюдение $(66,8 \%)$, значительно реже выполняли классическую каротидную эндартерэктомию с артифициальной пластикой - 19 случаев $(10,5 \%)$, протезирование внутренней сонной артерии - 13 наблюдений $(7,2 \%)$, резекцию с реимплантацией внутренней сонной артерии -28 наблюдений $(15,5 \%)$. Максимальная длительность операции 2 ч 10 мин. Средняя длительность пережатия сонных артерий составила $(26,1 \pm 6,9)$ мин (от 16 до 50 мин). 
Во всех случаях измеряли ретроградное давление. В соответствии с опубликованными данными, мы разделили пациентов на группы в соответствии с уровнем ретроградного давления: 50 мм рт. ст. и более - 71 наблюдение, 40 мм рт. ст. - 52 наблюдения, 35 мм рт. ст. - 36 случаев, 25 мм рт. ст. - 22 наблюдения. Всего временный внутрипросветный шунт был использован в 12 случаях (6,6\%). В 4 наблюдениях при ретроградном давлении 25 мм рт. ст. и в 2 наблюдениях при ретроградном давлении 35 мм рт. ст. В 3 из них диагностирован незамкнутый артериальный круг большого мозга (2 - полная задняя трифуркация внутренней сонной артерии, 1 - отсутствие задней соединительной артерии). В 2 случаях шунт применен при окклюзии контралатеральной внутренней сонной артерии. В 1 наблюдении он использован у пациента с сосудисто-мозговой недостаточностью IV степени. В 4 случаях причина применения шунта не найдена. В 5 наблюдениях мы перешли на общую анестезию (начало исследования), в остальных 7 закончили операцию под местной анестезией. Количество полученных осложнений не отличалось от опубликованных данных: острый коронарный синдром - 1,1\%, «малый» инсульт - 1,1\%, транзиторная ишемическая атака - 1,1\%, невропатия подъязычного нерва $-3,3 \%$, гематома послеоперационной раны - 11,6\%, дисфония - 8,3\%, пара-, анестезия послеоперационной раны - 34,8\%. Таких осложнений, как летальный исход, острый инфаркт миокарда отмечено не было.

На данный момент нет достоверных способов объективизации толерантности головного мозга к ишемии. Измерение ретроградного давления и анатомо-топографическая индивидуализация заболевания не могут служить предикторами временного внутрипросветного шунтирования. Использование регионарной анестезии при каротидной эндартерэктомии позволяет безопасно и эффективно оценить неврологический статус. Применение региональной анестезии позволяет сохранить ауторегуляцию сосудов головного мозга, уменьшив тем самым частоту использования ВВШ до $6,6 \%$, а частоту периоперационных инсультов до 1,1\%. Методика не требует применения дорогостоящей аппаратуры и высококвалифицированных кадров.

Обеспечение эффективной региональной анестезии при каротидной эндартерэктомии является важным компонентом в арсенале методов анестезиолога.

Оценивали артериальное русло исходно ультразвуковым исследованием или МРТ-томографией с контрастированием.

\section{Прения}

В.Н.Вавилов (председатель). В каротидной хирургии существует несколько проблем, которые нуждаются в разрешении, в том числе выбор способа анестезии: общая, местная или регионарная. Доклад интересный, следует поздравить коллектив авторов с достигнутыми результатами.

Поступил в редакцию 31.05.2017 г.

230-е заседание 16.09.2015 г.

Председатель - В.М.Седов

\section{ДЕМОНСТРАЦИЯ}

Д. Д.Купатадзе, В.В.Набоков, А.П.Иванов, Ю.Ю.Махин (кафедра хирургических болезней детского возраста СПбГПМУ). Случай ишемии нижних конечностей у младенца.

Мальчик в возрасте 1 год 7 мес поступил в отделение реанимации с диагнозом: «сепсис, полиорганная недостаточность, ишемия нижних конечностей». На ангиограмме выявлен восходящий тромбоз сосудов нижних конечностей и аорты. В анамнезе - указания на перенесенную клиническую смерть, тяжелый септический шок. Объективно отмечалась гангрена левой стопы, голени до коленного сустава, отсутствие пульсации и гипотермия на правой нижней конечности. Учитывая тяжесть состояния, степень ишемии и развитие гангрены на фоне сепсиса, поставлены показания к оперативному вмешательству: ампутации и тромбэктомии. Произведены ампутация на границе средней и нижней третей левого бедра, тромбэктомии катетером Фогарти из аорты и артерий конечности, удалено значительное количество тромботических масс серо-темно-вишневого цвета, получен адекватный кровоток. Послеоперационный период тяжелый, лоскуты культи бедра розовые, ногтевые фаланги пальцев правой стопы - с участками сухого некроза, пульсация определяется, контрактур в правой нижней конечности нет. Получал антикоагулянтную, дезагрегантную и антибактериальную терапию, выздоровление.

Oтветы на вопросы. В критических случаях для профилактики тромбозов вен у детей используем фраксипарин.

\section{Прения}

В.М.Седов (председатель). Доктора встретились с чрезвычайно тяжелый случаем ишемии нижней половины туловища у младенца. Удалось не только спасти жизнь, но и сохранить одну ногу благодаря умелым действиям детских ангиохирургов.

\section{дОкЛАдЫ}

1. Д. Д.Купатадзе (кафедра хирургических болезней детского возраста СПбГПМУ). Проблемы детской ангиохирургии в Северо-Западном регионе РФ.

В ангиомикрохирургическом отделении университета на протяжении последних 30 лет обследуют и лечат детей (более 1000 пациентов в год) с пороками развития артерий, вен, лимфатической системы, тромбозами, травмами и последствиями повреждений периферических артерий и вен, а также больных, нуждающихся в аутотрансплантации тканей (кишка, кость, яичко, почка, «свободные» лоскуты). Осуществляют реплантации и реконструкции сегментов конечностей, удаление образований (злокачественных и доброкачественных) в проекции магистральных сосудистонервных пучков. Клиническую картину оценивают с учетом классических ангиохирургических синдромов, а операции осуществляют, как правило, с элементами микрохирургической техники и в $20 \%$ случаев с применением микрохирургической техники оперирования. В каждом отдельном случае учитываются индивидуальные и возрастные особенности пациентов. Оперативная техника включает в себя прецизионное разъединение тканей диссектором и электрокаутером с минимальной кровопотерей. По специальному алгоритму оценивают ситуацию и принимают решение в ургентных ситуациях, в течение 30 лет обеспечивается круглосуточная ангиохирургическая помощь (на общественных началах). Большой проблемой является отсутствие детской ангиохирургии как специальности и недостаточное знакомство 
педиатров и детских хирургов с особенностями клинической картины заболеваний и повреждений сосудов у детей.

Ответы на вопросы. Ангиохирургических детских квот нет.

\section{Прения}

И.А.Пятериченко. Специальности «взрослая сосудистая хирургия» тоже нет, вероятно, тенденция к укрупнению специальностей в Минздраве не даст возможности ввести новую специальность «детская ангиология» или «детская ангиохирургия».

А.С.Немков. Санкт-Петербургу в значительной степени повезло, что у нас Д.Д.Купатадзе организовал детскую ангиохирургию в Педиатрическом институте, ныне в Университете. В большинстве городов нашей страны к детской сосудистой хирургии привлекают взрослых сосудистых хирургов совместно с детскими и общими хирургами. По сути, Д. Д.Купатадзе прав, когда ратует за выделение отдельной специальности «детская ангиохирургия», так как множество нюансов детской ангиологии абсолютно отсутствуют во взрослой сосудистой хирургии, что недопустимо на современном уровне развития сердечно-сосудистой хирургии.

В.М.Седов (председатель). Проблема ясна - отсутствие детской сосудистой хирургии. Все детские хирурги должны владеть приемами сосудистой хирургии. Необходимо создавать научные школы и обучать молодых врачей основам ангиохирургии.

2. М.С.Богомолов (Кафедра факультетской хирургии ПСПбГМУ им. акад. И.П.Павлова). Преимущества использования современных раневых покрытий при лечении трофических язв различного генеза.

В связи с растущей частотой сосудистых заболеваний и сахарного диабета совершенствование методов лечения хронических ран и язв различного генеза на нижних конечностях становится все более актуальным аспектом работы хирургов. Одним из путей улучшения результатов и сокращения сроков лечения больных этой группы является более активное использование современных перевязочных средств и раневых покрытий, обеспечивающих постоянное ведение ран в условиях влажной среды.

Выбор типа повязки зависит от стадии раневого процесса и глубины раневого дефекта. При высоком исходном уровне бактериальной обсемененности показано использование водорастворимых мазей с антибактериальной активностью («Офломелид», «Браунодин») или сетчатых повязок с повидон-йодом («Пови Силкофикс»). Применение этих средств позволяет в течение 2-3 нед добиться полной санации раны от раневой инфекции и, как следствие, активизации роста грануляций у 90-95\% пациентов. После устранения инфекции переходят к применению окклюзирующих гидроколлоидных повязок («Фиброколд Аргентум»), смену которых производят раз в 5-7 дней, в зависимости от степени экссудации раны. Применение этого алгоритма лечения обеспечивает полную эпителизацию поверхностных дефектов кожи в течение 10-14 дней. При глубоких дефектах (когда дно раны достигает подкожной клетчатки или даже сухожилий или костей) показано применение мембран из нативного коллагена («Коллост»). Для предотвращения высыхания поверхности раны и имплантированной коллагеновой мембраны в период между перевязками успешно использовались также гидроколлоидные раневые покрытия. Имплантацию мембран выполняли с интервалом 5-7-14 дней.
В редких случаях (при избыточной экссудации или при сниженной сопротивляемости окружающей рану кожи) у пациентов с язвами, возникшими на фоне лимфовенозной недостаточности, применение методики ведения ран в условиях влажной среды может сопровождаться развитием перифокального дерматита. В таких ситуациях показало свою высокую эффективность использование губчатых повязок («Фибросорб»), обеспечивающих вертикальную абсорбцию экссудата, и йодсодержащих сетчатых повязок («Пови Силкофикс»).

В отличие от язв венозной этиологии, ишемические язвы чаще характеризуются низким уровнем экссудации или ее отсутствием. В связи с этим при лечении таких «сухих» ран требуется их увлажнение, стимулирующее аутолиз некротизированных тканей и рост грануляций. Для этого применяют гидрогелевые средства (повязки «Фиброгель AG» и гель «Фиброгель $\mathrm{AG}$ плюс»).

Заключение. Применение современных методик этапного (с учетом стадии процесса) использования различных средств для местного лечения ран позволяет добиться полного заживления длительно незаживающих ран и язв различного генеза у большинства пациентов с хроническими гнойно-некротическими изменениями на стопе. Для успешного лечения трофических язв нижних конечностей необходимо использовать комплексный подход, учитывающий патогенез заболевания, являющегося причиной трофических расстройств.

\section{Прения}

В.М.Седов (председатель). Отметил сложность и важность корректного лечения трофических язв различного генеза. Комплексный подход, продемонстрированный докладчиком, показывает, что использование современных принципов лечения длительно незаживающих язв позволяет справиться даже с такими случаями, которые ранее были показанием к ампутации конечности. Поздравил автора с успешной работой.

Поступил в редакцию 31.05 .2017 г.

\section{1-е заседание 21.10.2015 г.}

Председатель - Г.Ю.Сокуренко

\section{ДЕМОНСТРАЦИЯ}

В.М.Пизин, А.Я.Бедров, В.М.Кондратьев, А.А.Хряпа (кафедра и клиника факультетской хирургии и госпитальной хирургии № 1 ПСПбГМУ им. акад. И.П.Павлова). Случай успешной сочетанной операции у больной с ранее выполненным протезированием аортального клапана и мультифокальным поражением брюшной аорты и ее висцеральных ветвей.

Пациентка X., 65 лет, 5 лет назад перенесла операцию протезирования аортального клапана механическим протезом по поводу дегенеративного критического стеноза аортального клапана. В связи с похуданием, болями в надчревной области и выраженной артериальной гипертензией она обследована в клинике факультетской хирургии. При MCKT в сосудистом режиме и ангиографии с контрастированием выявлены гемодинамически значимые стенозы обеих почечных артерий и чревного ствола. В мае 2015 г. больной выполнена сочетанная операция: баллонная ангио- 
пластика и стентирование правой и левой почечных артерий в ангиографической операционной. Больная была переведена в сосудистую операционную, где ей выполнена операция: тромбэктомия из аорты, аортобедренное бифуркационное шунтирование с имплантацией нижней брыжеечной артерии в ствол протеза, аорто(протезо)-верхнебрыжеечное шунтирование синтетическим протезом 10 мм лапаротомным доступом. Послеоперационный период без осложнений. Через полгода прибавка массы тела составила 8 кг.

Ответы на вопросы. Нефракционированный гепарин под контролем АПТВ и на 4-е сутки аспирин, затем медикаментозная поддержка - Варфарин под контролем МНО до 2,0-2,5 и Тромбоасс. По стандартам, после протезирования аортального клапана показано назначение именно Варфарина, так как отсутствуют результаты исследований других препаратов в данной ситуации.

Невозможность стентирования и использования других способов вследствие выраженного стеноза нижних брыжеечных артерий.

\section{Прения}

Г.Ю.Сокуренко (председатель). Несмотря на сложности в лечении пациентки, учитывая мультифокальное поражение сосудов, после операции отмечено улучшение качества жизни, увеличение массы тела на 8 кг и исчезновение перемежающейся хромоты, что является блестящим результатом, поздравляем коллектив с большим успехом.

\section{ДОКЛАД}

Г.И.Попов, П.В.Попрядухин, В.Н.Вавилов, И.П. Добровольская, В.Е.Юдин, Г.Ю.Юкина (ПСПбГМУ им. акад. И.П.Павлова, Институт высокомолекулярных соединений РАН). Возможно ли создание тканеинженерного сосудистого имплантата без использования клеточного материала?

В современной сосудистой хирургии остается нерешенной проблема сосудистых протезов малого диаметра. Одним из предполагаемых решений является создание тканеинженерного сосудистого имплантата (ТИСИ).

Цель работы: комплексная оценка биорезорбируемого протеза из L-полилактида (ПЛА) и определение возможности его использования в качестве матрицы для получения ТИСИ. Изучение процессов интеграции биодеградируемого сосудистого протеза в сосудистое русло без предварительного культивирования на нем клеточного материала.

Методом электроформования (Nanon 01A) получены трубчатые графты (внутренний диаметр 1,1 мм) на основе нетканого материала из нановолокон ПЛА, размер пор от 10 до 30 мкм. Мезенхимальные стволовые клетки (МСК), полученные из жировой ткани крысы, культивировались на пленочных препаратах ПЛА и на образцах сосудистых графтов. Разработанные графты имплантировали в качестве линейных протезов в брюшную аорту крыс $(\mathrm{n}=18)$. Полученный материал подвергали гистологическому исследованию, выполняли электронную микроскопию, иммуногистохимическое исследование $\left(\mathrm{CD} 31^{+}\right)$

$\mathrm{B}$ опытах in vitro MCK, полученные из жировой ткани крысы, пролиферировали как на пленочных препаратах ПЛА, так и на образцах графтов. Через 1 мес формируются эндотелиальная выстилка $\left(\mathrm{CD} 31^{+}\right)$и субэндотелиальный слой на всем протяжении графтов, начинается врастание соединительной ткани в толщу стенки протеза, отмечаются первые признаки биодеградации волокон полимера. Через 14 мес стенка протеза представлена соединительной тканью с импрегнированными в нее элементами волокон полимера, на внутренней поверхности располагается неоинтима, представленная эндотелиальными клетками и субэндотелиальным слоем, образованным, в свою очередь, коллагеновыми и эластиновыми волокнами. Через 16 мес $(\mathrm{n}=3)$ происходит тотальная биорезорбция полимера, в результате стенка образованного «сосуда» состоит из соединительной ткани, развивается аневризма всей зоны реконструкции. Проходимость графтов составила $88 \%$.

В опытах in vivo доказана безопасность, биосовместимость полученной матрицы из ПЛА. Низкие механические свойства соединительной ткани, заместившей ПЛА, явились причиной образования аневризмы зоны реконструкции, что свидетельствует о необходимости предварительного культивирования клеточного материала на матрице in vitro.

Ответь на вопросы. Причиной аневризм в анастомозах является образование соединительной ткани в большом количестве.

Аневризмы возникают по ходу анастомоза. Мы изучаем причины этого явления, аневризмы образовывались во всех трех случаях после культивирования.

Проводились гидродинамические испытания с метиленовым синим и водой под давлением. Тем не менее, невозможно полностью моделировать вязкость крови и другие особенности естественного кровотока, к тому же нас интересуют характеристики не матрицы, а готового синтетического протеза.

Иммунный ответ должен быть сведен к минимуму, так как идет распад матрицы до молочной кислоты.

Работа в этом направлении будет окончена. Мы будем исследовать армированные матрицы и разрабатывать новые протезы высокой прочности.

Клеточные культуры не растут на синтетике. Должна быть питающая подложка. Мы вшиваем спецпакеты со средой для питания, как и ученые из США.

Над проблемой получения графтов длиной 10 см и диаметром 3-4 мм работают многие институты, но пока результатов нет.

\section{Прения}

А.С.Немков. Огромное спасибо за отличный доклад. Докладчик поставил себе невыполнимую задачу. Японские хирурги делают подобные исследования, протезируя сосуды низкого давления - вены. Вы поставили себе максимальную задачу - создать структуру артерий. Это сложно. Л.В. Лебедев, используя лавсановый протез во время операции, пропитывал его кровью, после чего он хорошо работал за счет прорастания своими клетками - формировалась неоинтима. Фактически это был новый сосуд: каркас синтетический и неоинтима своя собственная. При этом важнейшее значение имеет размер пор в стенке протеза. Эндотелизация собственными клетками будет при восстановлении кровотока, медикаментозная поддержка, возможно, также будет играть существенную роль. Спасибо за хороший доклад.

И.А.Пятиреченко. Блестящая по настрою работа. Взять самую сложную модель, много работать с проблемой. Пусть результат отрицательный, однако появляются новые идеи и возможности: что-то отбрасывается, а что-то «идет в практику». Необходимо вести такую работу. Спасибо за труд. 
В.Н.Вавилов. Проблема эта частная и трудная. Нужно много и серьезно этим заниматься. Надеемся, появятся новые мысли.

Г.Ю.Сокуренко (председатель). Эти работы ведутся десятилетиями - экофлон, пуповина, трахея В.А.Гусинского. Сейчас мы пытаемся понять биологические механизмы происходящих в графте процессов, чтобы создать сосуд нового поколения, в котором прочность будет обеспечена синтетическими нитями, а вживление обеспечат новые клеточные технологии. Спасибо за доклад!

Поступил в редакцию 31.05.2017 г.

\section{2-е заседание 18.11.2015 г.}

Председатели - А.Б.Зорин, И.А.Пятериченко

\section{ДЕМОНСТРАЦИИ}

1. А.Б.Зорин, А.А.Бояркин, А.И.Борисов (Городской хирургический Центр на базе СПбГБУЗ «Городская многопрофильная больница № 2»). Отдаленный (19-летний) результат успешной хирургической коррекции расслаивающей аневризмы аорты 1-го типа.

Пациент 54 лет, профессор, заболел внезапно во время чтения лекции: появилось головокружение, потерял сознание. Был доставлен машиной «скорой помощи» в Покровскую больницу, где при эхокардиографическом исследовании был поставлен диагноз: расслаивающая аневризма восходящей аорты. В срочном порядке больной был взят в операционную. Выполнена стернотомия, вскрыт перикард. Обнаружен гемоперикард, разрыв стенки восходящей аорты. Разрыв зашит, выполнено бандажирование восходящей аорты синтетическим протезом. Послеоперационный период протекал тяжело в связи с перенесенным геморрагическим шоком, тяжелой операцией, массивными гемотрансфузиями. Больной наблюдается в течение 19 лет. Переносит обычные физические нагрузки, контролирует артериальное давление. Дополнительная операция не потребовалась.

Ответы на вопросы. Принимаю следующие лекарства: Кордарон, Кардиомагнил, Карсил, Занидиф, Нифекард, Физиотенз.

\section{Прения}

И.А.Пятериченко. У больного синдром бинодальной слабости - будет поставлен кардиостимулятор. Обычная эхокардиография дает нам все показатели работы сердца, другие исследования не понадобились.

2. А.Б.Зорин, В.К.Новиков, Т.Б. Ливанова, В.А.Кочетова, И.А.Пятериченко (кафедра и клиника ХУВ № 1 ВМедА им. С.М.Кирова, Городской кардиохирургический Центр на базе СПбГБУЗ «Городская многопрофильная больница № 2). Отдаленный (27-летний) результат успешной хирургической коррекции тотального аномального дренажа легочных вен.

В 1988 г. в клинику хирургии усовершенствования врачей № 1 ВМедА им. С.М.Кирова поступил пациент 12 лет, у которого при рентгенологическом исследовании был выявлен симптом «снежной бабы» - изменения правого и левого контуров сердечной тени - характерный признак аномального дренажа легочных вен в правое предсердие в сочетании с дефектом межпредсердной перегородки. Диагноз был под- твержден при зондировании полостей сердца. Выполнена радикальная операция - пластика межпредсердной перегородки большим перикардиальным лоскутом с перемещением устьев легочных вен в левое предсердие. Таким образом было сформировано соустье между легочными венами и полостью левого предсердия через межпредсердную перегородку с ликвидацией сброса крови из левого предсердия и легочных вен в правое предсердие. Послеоперационный период протекал без осложнений. В дальнейшем пациент наблюдался педиатрами и взрослыми кардиологами. В настоящее время работает по специальности, женат, воспитывает 2 детей. Цель демонстрации - показать хороший отдаленный результат радикальной операции при аномальном дренаже легочных вен.

Ответы на вопросы. Очень трудная анатомическая ситуация, и выбор других вариантов был затруднителен. Диагностика не вызывала трудностей.

\section{Прения}

А.С.Немков. Радикальная коррекция таких пороков сердца дает хорошие отдаленные результаты. Мы видим это у данного пациента.

А.Б.Зорин. Имею практику лечения трех таких больных, но этот случай - самый сложный. «Снежная баба» - симптом сбора полых вен, других вариантов объяснить этот симптом нет.

\section{дОКлАД}

А.Б.Зорин (Городской кардиохирургический центр на базе СПбЗБУЗ «Городская многопрофильная больница № 2»). Развитие кардиохирургии в Ленинграде - СанктПетербурге.

Развитие кардиохирургии в Ленинграде связано с именем Петра Андреевича Куприянова - генерал-лейтенанта медицинской службы, возглавившего в послевоенное время клинику факультетской хирургии Военно-медицинской академии. Первые операции при врожденных пороках сердца, выполненные П.А.Куприяновым, относятся к 1953 г. : ликвидация открытого артериального протока, устранение стеноза легочной артерии, произведена аллопластика аорты при ее коарктации. В 1953-1954 гг. клиника активно занималась освоением гипотермии для выполнения операций на остановленном сердце. Первую операцию в условиях гипотермии П.А.Куприянов выполнил в 1954 г. А.П.Колесов одним из первых в стране выполнил операции по поводу аневризмы сердца, двойной дуги аорты, недостаточности митрального клапана, разработал правосторонний доступ для митральной комиссуротомии. В 1958 г. П.А.Куприянов организовал первую в стране кафедру анестезиологии и реаниматологии в ВМА, что оказало существенное влияние на развитие сердечно-сосудистой хирургии в нашей стране. В 1957 г. в Ф.В.Баллюзеком и Н.И.Ермиловым в ВМА впервые был собран аппарат искусственного кровообращения ИСЛ-1 (в последующем он изготавливался на заводе «Красногвардеец»), и его первое клиническое применение относится к маю 1959 г. С 1962 г. А.П.Колесов стал выполнять открытые операции на клапанах сердца, в частности аннулопластику митрального клапана, протезирование митрального клапана. Существенного прогресса клиника под руководством А.П.Колесова достигла при лечении врожденных пороков сердца: дефектов межпредсердной и межжелудочковой перегородок, подклапанного 
стеноза легочного ствола, тетрады Фалло, открытого атриовентрикулярного канала. Большого прогресса клиника, возглавляемая А.П.Колесовым, достигла и в хирургическом лечении приобретенных пороков сердца: протезирование митрального и аортального клапанов при их ревматическом поражении .

В клинике госпитальной хирургии 1-го ЛМИ им. акад. И.П.Павлова под руководством проф. Ф.Г.Углова работала группа врачей, активно и успешно изучавших врожденные и приобретенные пороки сердца, прежде всего митральные. В соседней клинике 1-го ЛМИ, клинике факультетской хирургии, проф. В.И.Колесов - ученик П.А.Куприянова — c 1955 г. активно разрабатывал операции при ишемической болезни сердца, что позволило ему в 1964 г. выполнить первый в мире анастомоз левой внутренней грудной артерии с огибающей артерией. После этого в клинике факультетской хирургии стали регулярно выполнять операции маммарокоронарного анастомоза при ИБС.

Таким образом, ВМедА с 1950-х годов обеспечила существенное развитие зарождающейся новой специальности - кардиохирургии, она обеспечила целый каскад научных исследований, на базе которых прогресс хирургического лечения многих врожденных и приобретенных заболеваний сердца стал возможен во многих учреждениях нашего города и нашей страны.

Поступил в редакцию 31.05.2017 г.

\section{3-е заседание 16.12.2015 г.}

Председатели - А.С.Немков, Г.Ю.Сокуренко

\section{ДЕМОНСТРАЦИИ}

1. К.А.Андрейчук, Д.Н. Дойников, Г.Ю.Сокуренко, В.Ф.Хлебов, С.В.Кузнецов, Д.А.Шелухин (Всероссийский центр экстренной и радиационной медицины им. А.М.Никифорова МЧС России). Случай успешного лечения больной с посттравматической ложной аневризмой перешейка аорты.

Пациентка О., 34 лет, была в плановом порядке госпитализирована в отделение сердечно-сосудистой хирургии 18.06.2014 г. в связи с выявленной ранее аневризмой грудной аорты. Из анамнеза известно, что в 2002 г. в результате падения с высоты 7-го этажа получила тяжелую сочетанную травму, включавшую в себя перелом костей таза с нарушением целостности тазового кольца, компрессионный перелом поясничных позвонков, перелом правой ключицы, разрыв печени с гемоперитонеумом, ушиб грудной клетки и легких с двусторонним пневмотораксом. Перенесла множественные оперативные вмешательства, выздоровела. Томографическое исследование грудной клетки не проводилось.

В 2014 г. при рутинной флюорографии было выявлено образование в верхнем средостении, проводилась дифференциальная диагностика с лимфоаденопатией средостения. При КТ-ангиографии выявлена аневризма перешейка аорты размерами $52 \times 45$ мм, расположенная в 20 мм от устья левой подключичной артерии. При изучении данных томографии обнаружено, что стенка аневризмы структурно неполноценна, а сама аневризма является ложной, развившейся вследствие децелерационного повреждения при кататравме. Учитывая характер заболевания, пациентке было предложено оперативное вмешательство. Обсуждались две возможные методики: эндопротезирование или открытое протезирование аорты. Пациентка настаивала на открытой операции ввиду более прогнозируемого отдаленного результата.

Операция 22.06.2014 г. При левосторонней торакотомии в четвертом межреберье - спаечный процесс между верхней долей левого легкого и аортой. Выполнена перикардотомия и канюляция ушка левого предсердия. Учитывая молодой возраст пациентки и локальное поражение аорты дистальная канюляция выполнена не на бедре, а в нисходящей аорте тотчас над диафрагмой из торакотомического доступа. Налажен левопредсердно-аортальный обход посредством центрифужной помпы. Аорта выделена проксимальнее и дистальнее аневризмы и протезирована графтом B|BRAUN SilverGraft $22 \mathrm{~mm}$. Общая интраоперационная кровопотеря составила 600 мл, длительность байпасса - 98 мин. Экстубирована через 4 ч после операции, переведена из отделения интенсивной терапии на 2-е сутки. Послеоперационный период протекал без осложнений, заживление раны первичным натяжением. Выписана на 8-е сутки. Наблюдается в течение 18 мес, жалоб нет, трудоспособность и социальная активность восстановлены полностью, субъективно оценивает качество жизни как высокое.

Цель демонстрации - показать редкое клиническое наблюдение длительно существовавшей ложной аневризмы аорты и возможности открытого хирургического лечения у молодой пациентки.

Ответы на вопросы. Пациентка была против эндоваскулярного эндопротезирования, так как в отдаленном периоде результаты неизвестны. Жалоб не было, и аневризму обнаружили на флюорограмме. Отказались от бедреннопредсердного подключения с АИК, так как наш вариант более косметичен, с учетом возраста больной.

\section{Прения}

А.С.Немков. Поздравил с успешной операцией бригаду хирургов, которая справилась с труднейшей проблемой.

2. К.А.Андрейчук, М.И.Генералов, Г.Ю.Сокуренко, Д.Н. Дойников, Е.В.Киселева, В.Ф.Хлебов, О.А.Русанов (Всероссийский центр экстренной и радиационной медицины им. А.М.Никифорова МЧС России; Российский научный центр радиологии и хирургических технологий). Случай успешного лечения больной «высокого риска» с разрывом аневризмы грудной аорты.

Пациентка М., 88 лет, была экстренно госпитализирована в клинику в тяжелом состоянии с подозрением на острый коронарный синдром в связи с жалобами на интенсивные боли в груди, эпизод потери сознания, гипотензию. Из анамнеза было известно о наличии выявленной около 5 лет назад аневризмы нисходящей грудной аорты, в хирургическом лечении которой больной было отказано ввиду возраста и тяжести сопутствующих заболеваний: тяжелой артериальной гипертензии, трех перенесенных инфарктов миокарда (последний в 2007 г.), постоянной формы фибрилляции предсердий, недостаточности кровообращения 3-го класса.

При обследовании данных за острое повреждение миокарда выявлено не было. Заподозрено наличие осложненной аневризмы грудной аорты, что подтвердилось при КТ-ангиографии. По данным исследования, имелась аневризма, расположенная в 40 мм дистальнее дуги, с максимальным диаметром 87 мм, протяженностью 110 мм, осложненная разрывом, гематомой средостения и субтотальным гемотораксом слева. По данным других обследований, была обнаружена 
анемия (Нb 78 г/л) и выраженное снижение сократительной функции миокарда (ФВ $30 \%)$.

Были определены показания к экстренной операции для спасения жизни больной. Методика эндопротезирования грудной аорты (TEVAR) — единственно возможная и переносимая для пациентки. Был экстренно заказан после соответствующих параметрических расчетов эндопротез необходимых размеров. Операция была выполнена через 8 ч от момента поступления пациентки, когда эндопротез был доставлен из Москвы.

Операция 18.06.2015 г.: эндопротезирование аневризмы грудной аорты через правый бедренный доступ системой Bolton Medical Relay Plus 40×195 мм в условиях гибридной операционной. Операция прошла без осложнений, экстубация через 12 ч. В послеоперационном периоде отмечалось психическое расстройство, потребовавшее лечения в отделении реанимации в течение 3 сут. Больная была выписана на 15-е сутки в удовлетворительном состоянии. При наблюдении в течение полугода - активна, жалоб не предъявляет. При контрольной КТ-ангиографии - оптимальный результат.

Цель демонстрации - показать возможности эндоваскулярного протезирования разрыва аневризмы грудной аорты, как единственного способа спасения пациентов группы крайне высокого риска.

Ответы на вопросы. Подобные операции выполняли эпизодически. Мы получаем стентграфты даже для экстренных операций на аорте. Мы не применяли непункционный способ установки стентграфта, так как был выражен кальциноз артерий и аорты. Концентрация креатинина была в норме.

\section{Прения}

В.К.Сухов. Оба выступления очень интересны, мастерски выполненная работа. Метод эндоваскулярный, чрескожный. Доступ усложняет течение послеоперационного периода. Операцию можно выполнять под местной анестезией. Очень приятно, что в С.-Петербурге появились новые учреждения, где выполняют подобные операции. Рентгенохирурги при аневризмах аорты не очень нужны, так как сосудистые хирурги сами владеют этими методами. При рентгенохирургических операциях орган остается неподвижным.

А.С.Немков. Поздравил коллектив авторов и хирурга за прекрасно организацию помощи этим пациентам. Имеется тенденция в последние годы к выполнению эндоваскулярных операций в таких случаях. Возрастные больные плохо переносят большие хирургические доступы, но отказываться от традиционных операций не следует.

\section{ДОКЛАД}

Г.Ю.Сокуренко, К.А.Андрейчук, А.В.Шатравка (Всероссийский центр экстренной и радиационной медицины им. А.М.Никифорова МЧС России и Городская больница № 26). Каротидная реваскуляризация в раннем периоде ишемического инсульта.

Возможность и необходимость выполнения каротидной эндартерэктомии (КЭАЭ) в течение первых 6 нед после развития ишемического инсульта продолжает оставаться дискутабельной. Основные опасения связаны с высоким риском развития геморрагической трансформации ишемического очага и закономерным ухудшением состояния пациента. Тем не менее, преимущества ранних КЭАЭ были продемон- стрированы в целом ряде сообщений и рекомендательных документов. С другой стороны, до сих пор остаются не до конца проясненными конкретные вопросы селекции пациентов и временные интервалы, оптимальные для проведения оперативного вмешательства. Так, по мнению некоторых авторов, КЭАЭ может быть безопасно, не увеличивая риски, произведена даже в острейшем периоде ишемического инсульта для снижения вероятности развития повторных ишемических событий. Более того, ряд исследователей считают, что у пациентов с симптомами показания к КЭАЭ могут быть определены даже при отсутствии гемодинамически значимых (более $70 \%$ ) стенозов бифуркации сонной артерии. Наиболее спорной и малоизученной остается проблема неотложных вмешательств, производимых в первые 6 ч от момента развития инсульта. Суждения об активном хирургическом подходе в таких случаях весьма противоречивы. В частности, приводятся данные о крайне высоком риске вмешательства в первые 2 сут, которые, тем не менее, не подкреплены результатами доказательных исследований.

Многолетний опыт лечения более 200 пациентов со стенотическими поражениями сонных артерий в остром периоде ишемического инсульта продемонстрировал эффективность ранних реконструктивных вмешательств, которые позволяют достигнуть существенного улучшения неврологического статуса, значимо не увеличивая числа осложнений. При этом КЭАЭ обеспечивает предотвращение рецидивов ишемических событий.

По мнению авторов, КЭАЭ, произведенная в остром периоде ишемического инсульта, является эффективным и достаточно безопасным вмешательством, позволяющим предупредить развитие повторных нарушений мозгового кровообращения и улучшить реабилитационный потенциал. Однако залогом эффективности и безопасности является тщательный подбор пациентов.

Ответы на вопросы. При атероматозной бляшке со стенозом артерии до $30 \%$ операции не опасны, до $50 \%$ редко бывают инсульты, и больше $50 \%$ - чаще всего.

Для системного тромболизиса сроки после ОНМК не раньше 3-х суток, так как размер очага не всегда коррелирует с проявлениями ОНМК, поэтому очень осторожно проводим тромболизис. А оперативное лечение после ОНМК должно быть с индивидуальным подходом. При коме противопоказана хирургическая операция. Иногда до 6 ч после тромбоза можно пробовать тромболизис, а если больше 6 ч, то выждать 3 сут, и можно применять оперативное лечение. Тромбэктомия на 3-и сутки и реваскуляризация - это и предотвращение повторных инсультов.

Иногда окклюзия легче протекает, чем стеноз, так как меньше эпизодов эмболий, коллатерали включаются быстрее и лучше проводить тромбоэкстракцию. Для оценки кровотока лучше всего церебральная оксиметрия.

При экстренных ситуациях нельзя выполнять экстраинтракраниальные анастомозы, но в отдельных случаях их делают, хотя рандомизированные исследования показали незначительную разницу ЭИКА, по сравнению с консервативным ведением.

\section{Прения}

А.С.Немков. При стенозах и окклюзиях с обеих сторон, при выраженном дефиците кровотока выбор оптимальной хирургической тактики очень непростой. Благодарим авторов за прекрасный доклад и отличные пояснения. Спасибо.

Поступил в редакцию 31.05.2017 г. 